\title{
Effect of Ramadan Fasting on Sleeping Pattern and Nutritional Status of International Students at Nanjing- China \\ Falak Zeb ${ }^{1}$, Muhammad Haider Zaman', Ihtisham ul Haq ${ }^{3}$, Ijaz ul Haq ${ }^{4}$, Saeed $\mathrm{Ahmad}^{5}$
}

\section{ABSTRACT}

Objective: To investigate the effect of Ramadan fasting (RF) on sleeping pattern, nutritional status and nutrient intake of healthy international students.

Study Design: Cross sectional study.

Place and Duration of Study: The study was conducted at health centers of three universities i-e Nanjing University of Science and Technology, Nanjing Agriculture University and School of Public Health Nanjing Medical University, China in the month of May to June 2019.

Materials and Methods: A total 400 healthy male international students (18 to 38 years of age) from three universities of Nanjing city, China were registered through written consent. Data on anthropometrics, body composition, dietary intake, and physical activities were recorded through face to face interviews in a standard questionnaire while sleeping pattern was assessed by using polysomnography (PSG) technique at two time points (pre-fasting and post-fasting).

Results: The findings suggested non-significant difference between sleep latency (SL), sleep arousal (SA), and total sleep time (TST) after fasting compared to baseline (pre-fasting). The mean routine activities time $(p=0.000)$ and walking $(p=0.005)$ were significantly different before and after Ramadan. Mean values of hip circumference $(\mathrm{HC}), \%$ fat, body mass index (BMI) and basal metabolic rate (BMR) were also significantly $(p<0.05)$ changed. Moreover, after one month of RF, the nutritional status of the students was significantly improved based on BMI and WC classifications. The macronutrients, selected vitamins and minerals intake at pre-fasting was significantly $(p<0.05)$ higher than post-fasting. There was a significant positive correlation of dietary fat with body \%fat, BMI and BMR; total energy with sleep arousal (SA); dietary fiber with total sleep time (TST); vitamin A with sleep latency (SL), SA, BMI and BMR while vitamin D and E with SL and SA respectively.

Conclusion: Fasting in Ramadan fis not affecting the routine activities and sleeping pattern while regulating the optimal nutritional status.

Key Words: Nutritional Status, Ramadan Fasting, Sleeping Pattern, Total Sleep Time.

How to cite this: Zeb F, Zaman MH, Haq I, Haq I, Ahmad S. Effect of Ramadan Fasting on Sleeping Pattern and Nutritional Status of International Students at Nanjing- China. Life and Science. 2021; 2(3): 97-106. doi: http://doi.org/10.37185/LnS.1.1.160

This is an Open Access article distributed under the terms of the Creative Commons Attribution License (http://creativecommons.org/licenses/by/4.0), which permits unrestricted use, distribution, and reproduction in any medium, provided the original work is properly cited.

\begin{tabular}{|c|c|}
\hline $\begin{array}{l}{ }^{1,4} \text { Department of Nutrition and Food Hygiene } \\
\text { Nanjing Medical University, Nanjing, China }\end{array}$ & Introduction \\
\hline${ }^{1}$ Department of Human Nutrition and Dietetics & Ramadan fasting (RF) is one of the five basic pillars of \\
\hline National University of Medical Sciences, Rawalpindi & Islam, observed by approximately more than 1.6 \\
\hline${ }^{2}$ NSFZ, Nanjing Normal University, Nanjing, China & billion healthy adult Muslims for a full lunar month \\
\hline $\begin{array}{l}\text { Nutrition International Organization } \\
\text { Directorate General of Health, KРK }\end{array}$ & each year. ${ }^{1}$ RF does not require energy restriction; \\
\hline${ }^{5}$ Department of Biological Sciences & however, the intake of food and fluid become less \\
\hline National University of Medical Sciences, Rawalpindi & frequent that lead to changes in the nutritional and \\
\hline $\begin{array}{l}\text { Correspondence: } \\
\text { Dr. Falak Zeb }\end{array}$ & ost of the physicians, \\
\hline Department of Nutr & ents \\
\hline $\begin{array}{l}\text { Nanjing Medical University, Nanjing, China } \\
\text { E-mail: falak106@gmail.com }\end{array}$ & for proper diet plans on medical and nutritional \\
\hline Funding Source: Jiangsu Hi & ס \\
\hline onflict of Interes & changes, ${ }^{2}$ and an early heavy breakfast are taken just \\
\hline
\end{tabular}


before dawn called 'suhoor' and lunch is omitted. The fast is broken when the main meal is taken called 'iftar'.

Fasting regimens synchronize food ingestion with the times of optimal postprandial hormonal response due to dramatic caloric reduction during nighttime. Fasting actively impose the reprogramming of molecular mechanisms of energy metabolism, and improved body weight regulation. ${ }^{3}$ Taking food at abnormal circadian times is postulated that lead to circadian desynchronization, ${ }^{4}$ and following disruption of normal sleep patterns. During RF, sleeping times and patterns also change, ${ }^{5}$ due to breakfast to be consumed before dawn. Contradictory results have been reported regarding sleep latency (SL) and total sleep time (TST). ${ }^{6}$ Physical activity and exercise are also expected to be reduced during day time due to skipping food for longer time. In this way, fasting may lead to several biological processes; changes in hormonal and metabolic systems including circadian rhythms and thyroid function, ${ }^{8}$ serum cortisol, ${ }^{9}$ plasma leptin, ${ }^{10}$ adiponectin, ${ }^{11}$ and neuropeptide, ${ }^{12}$ that have been reported in health and disease conditions. Missing lunch and the long gap around 16 hours a day between major meals affect appetite, ${ }^{13}$ hormonal responses to food, and aspects of energy and glucose metabolism. The metabolism of the body may decrease in fasting state and it leads to a reduction in physical activity and basal metabolic rate (BMR).

Numerous studies have been suggested that during $\mathrm{RF}$, reduced energy and nutrient intake alter the body composition, but the results are varying and mostly depend on lifestyle factors. ${ }^{14-16}$ RF has been associated with variables of weight changes and anthropometry, ranging from modest weight gain to weight neutrality and weight loss, with a previously reported reduction in total calorie intake in some, but not all populations. ${ }^{17-20}$

Changes in sleeping pattern can affect various aspects related to metabolic and nutritional balance of the body, such as control of body mass, ${ }^{21}$ intake of food, ${ }^{22}$ glycemic index $(\mathrm{Gl}),{ }^{23}$ total cholesterol and triglycerol levels, ${ }^{24}$ and reduction in physical activity. Although, reduction in sleeping time could change the food intake pattern and lead to obesity as reported by previous studies. ${ }^{21-23}$ There should be some opposite casual sequence that food intake alters the sleeping pattern as indicated that excessive intake of dietary carbohydrate impairs the quality of sleep. ${ }^{25}$

During RF, patterns of food intake, sleep and physical activity are changed and subjects feel more relax as Ramadan encourages spiritual or religious activities. ${ }^{26-28}$ However, these changes have noteworthy nutritional, physical and physiological effects on the body, such as weight loss. The abnormal dietary intake is strongly associated with metabolic diseases such as obesity, cardiovascular diseases (CVD), diabetes mellitus (DM) and cancer when food intake pattern are altered. It is reported that protein, cholesterol, vitamin $E$ and polyunsaturated fatty acids were consumed in high amount during Ramadan in Tunisia. ${ }^{29}$ In another study, there was high consumption of carbohydrates and protein and low fat while energy intake remain unchanged. ${ }^{30}$

Previously, there are no studies conducted to investigate the effect of RF on sleeping pattern, physical activity, and body composition of students practicing fasting. The potential negative complications of RF on nutritional status and other lifestyle parameters of the students may impact their ability to successfully engage in active learning and experimental work at university. Currently, the flow of international students to China is increasing day by day due to "the belt and road" policy. Therefore, it was hypothesized that fasting has an impact on nutritional status, sleeping pattern and nutrient intake of international students.

\section{Materials and Methods}

This study was conducted at Department of Nutrition and Food Hygiene at Nanjing Medical University, China in the month of May to June 2019, and approved by the Research Ethical Committee of Nanjing Medical University, Jiangsu, China under grant number NJMUIRB (2018) 004. OpenEpi software was used to calculate the sample size considering $\alpha$ being $95 \%$, and $80 \%$ power chance of detecting with odd ratio of 2 with least extreme. A total of 400 healthy male students from three Universities of Nanjing city (Nanjing Medical University, Nanjing University of Science and Technology and Nanjing Agricultural University) were registered through written consent form. 


\section{Selection Criteria}

The participants were young adults between 18 to 38 years old and free from any acute or chronic diseases like diabetes, cancer, gastric diseases, liver failure, infectious diseases, renal and cardiovascular diseases etc at the time of study. They were not taking any medications or supplements and were nonsmokers. All participants were evaluated by a nutritionist who approved their participation in the study. The participants were volunteers and guided about the procedures and objectives before study initiation.

\section{Study Protocol}

Although the participants were aware about the timing and duration of RF, but in addition they were guided for fasting pattern. They were practicing fasting for 16 hours on daily basis for 30 days and consumed two hard meals including breakfast around $0300 \mathrm{hrs}$ and dinner at $1900 \mathrm{hrs}$.

\section{Data Collection}

At two time point's i-e pre-fasting and post-fasting, all participants were assessed by two trained assistant nutritionists in the health care facility of each university, followed by dietary data, anthropometric measurements, sleeping and physical activity pattern and possible adverse health effects related to fasting.

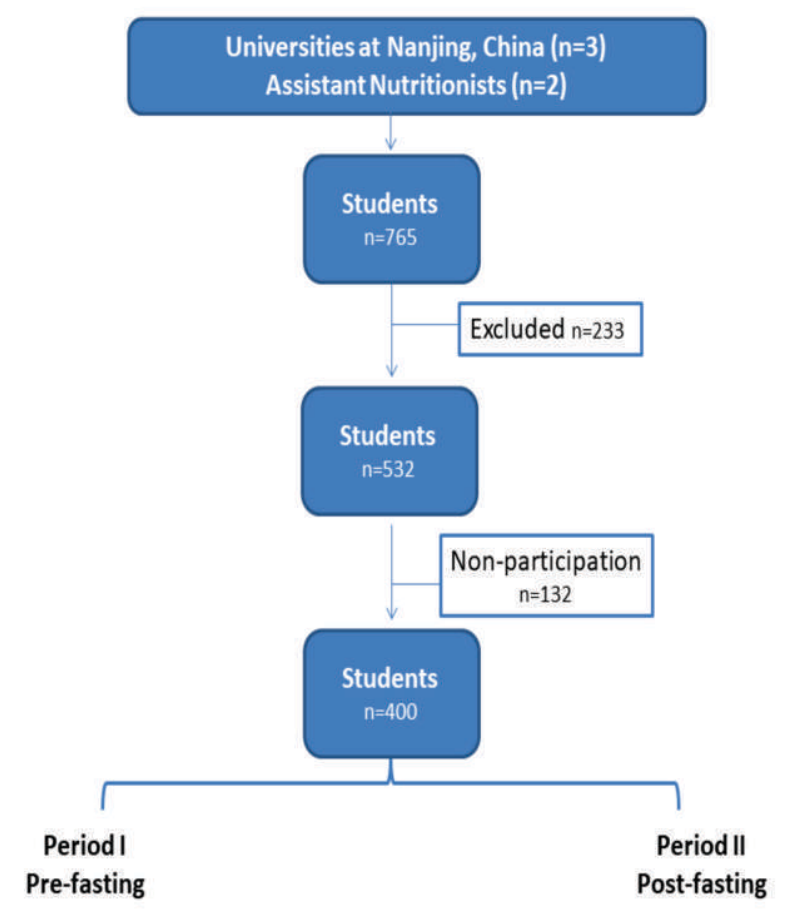

Flow chart 1: Study Participants

99

\section{Assessment of Sleeping and Physical Activity Patterns}

Polysomnography (PSG) technique was used to evaluate the sleeping pattern variables in the laboratory. EMBLA S7000 digital system (Embla Systems Inc, Medcare Flaga, Reykjavik, Iceland) was used to record the PSG in 30 second epochs. According to international 10 to 20 systems, electroencephalographic readings were recorded. ${ }^{31}$ The PSG used transcutaneous oximetry to measure oxygen saturation, a nasal cannula and thermistor to monitor the airflow, a sensor tracking the position of the trunk and belts to monitor thoracic and abdominal effort during sleep. According to the standard criteria of sleep classification, the PSG analyses were performed. ${ }^{32}$ The parameters included sleep latency, sleep efficiency and total sleep time (TST). In addition to these parameters typical sleep time, sleep arousal and typical awakening time was also recorded in the pre-PSG questionnaire. The physical activity pattern including time spent in routine activities, sedentary activities, walking, jogging, running and sports were evaluated by using a standard questionnaire.

\section{Assessment of Nutritional Status}

All anthropometrics were measured using standard procedures. A Sanny stadiometer with a precision of $0.1 \mathrm{~cm}$ (American Medical do Brasil, Ltd, Brazil) was fixed to the wall for height measurement. For evaluation of body weight, a Filizola scale (Star, Filizola, Brazil) with precision of $0.1 \mathrm{~kg}$ was used. BMI was calculated from weight $(\mathrm{kg}) /$ height $\left(\mathrm{m}^{2}\right)$ readings. Subjects were categorized on the basis of $\mathrm{BMI}$ as underweight (BMI $=<18.5)$, normal weight $(\mathrm{BMI}=18.5-24.9)$, overweight $(\mathrm{BMI}=25.0-29.9)$ and obese $(\mathrm{BMI}=>30)$ according to $\mathrm{WHO}$ classification (WHO, 2005). Body composition, body fat percentage (\%body fat) and basal metabolic rate (BMR) were evaluated by using bioelectrical impedance (BIA-Seca mBCA 515). A stretchable measuring tape was used to assess the waist circumference (WC) by placing it between iliac crest and lower rib margin around the midway of the abdomen. The readings were calculated to the nearest $0.1 \mathrm{~cm}$ and the nutritional status of the students was categorized on the basis of WC. Similarly, hip circumference $(H C)$ was also determined by using the measuring tape while 
placed around the buttocks to the nearest $0.1 \mathrm{~cm}$. In this way, waist to hip ratio (WHR) was calculated from the readings of waist and hip circumference and the student nutritional status was established as android shape $($ WHR $>0.8 \mathrm{~cm})$ and gynoid shape (WHR $<0.8 \mathrm{~cm})$.

\section{Dietary Intake Assessment}

Dietary intake was determined through a 24 hours dietary recall questionnaire for 3 consecutive days, filled one week before Ramadan (Pre-fasting) and in the last week of Ramadan (Post-fasting) through face to face interview. Students were instructed to provide all proper details of their consumed food and fluids, including products brand names and composition/ingredients for home-made food. Common household food utensils such as glasses, cups, teaspoons, bowls, plates and tablespoons in addition to individual food recipe or units were used for estimation of portion sizes. Assistant nutritionist inspected the questionnaires together with the participants to gain supplementary information about dietary intake where required. The NutriSurvey software (SEAMEO-TROPMED RCCNUniversity of Indonesia, 2007) was used for the quantitative analyses of caloric, macro and micronutrient intakes.

\section{Statistical Analysis}

Data was entered, cleaned and all statistical analyses were performed using SPSS (version 21.0, 2012, IBM Corporation). One-tailed paired-sample t-test with $\alpha=0.05$ was used for calculation of parameters between pre-fasting and post-fasting and were expressed as mean \pm standard deviation (SD) and/or frequency percentages. Tests for normality were included in the study model. For comparison withinsubject changes from pre-fasting, two-tailed paired sample t-tests were used. Pearson product moment correlation was applied for the association of dietary intake with sleeping pattern, physical activity and body composition. All reported p-values were associated with 2-tailed hypotheses and changes were considered significant at $95 \%$ level of significance.

\section{Results}

\section{General characteristics}

The baseline characteristics are presented in Table 1.

\begin{tabular}{|c|c|}
\hline \multicolumn{2}{|c|}{$\begin{array}{l}\text { Table 1: General characteristics, sleeping and physical } \\
\text { activity pattern of the students }(n=400)\end{array}$} \\
\hline $\begin{array}{l}\text { Parameters } \\
\text { Age (mean years) }\end{array}$ & $\begin{array}{l}\text { (Mean } \pm \text { SD)/ N (\%) } \\
27.51 \pm 5.84\end{array}$ \\
\hline Family members (mean) & $6.81 \pm 3.26$ \\
\hline \multicolumn{2}{|l|}{ Study level } \\
\hline Bachelor & $134(33.5)$ \\
\hline Master & $90(22.5)$ \\
\hline $\mathrm{PhD}$ & $176(44)$ \\
\hline \multicolumn{2}{|l|}{ Marital Status } \\
\hline Married & $117(29.25)$ \\
\hline Single & $283(70.75)$ \\
\hline \multicolumn{2}{|l|}{ Kitchen } \\
\hline Sharing & $271(67.75)$ \\
\hline Non-sharing & $129(32.25)$ \\
\hline
\end{tabular}

\section{Sleeping and physical activity pattern}

There was a non-significant difference in typical bedtime, sleep latency (SL), sleep arousal (SA), typical awakening time and total sleep time (TST) between pre and post-fasting shown in Figure 1.

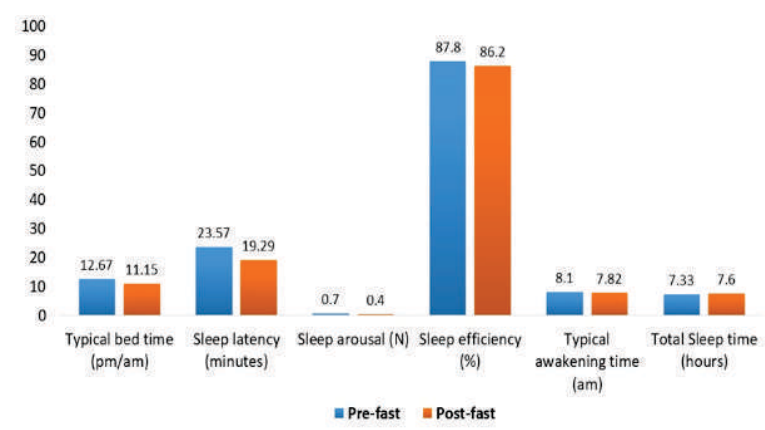

Fig 1: Sleeping pattern of the Students

The students in fasting group went to bed early, taking less time to fall asleep, wake up early and had more sleep duration than non-fasting group. The physical activity pattern in term of routine activities $(p=0.000)$ and walking $(p=0.005)$ were significantly different (Figure 2).

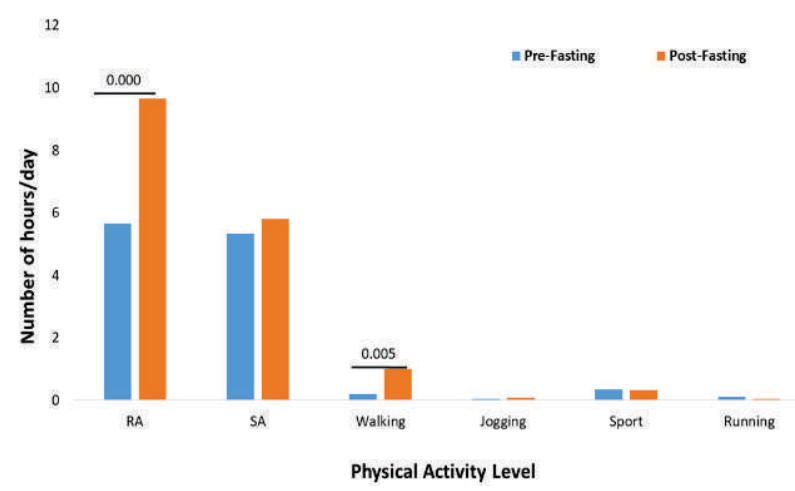

Fig 2: Physical activity level of the students 


\section{Body composition and nutritional status}

The mean weight, height, WC and WHR of both groups were non-significantly different, while $\mathrm{HC}, \%$ fat, BMI and BMR were significantly $(p<0.05)$ different. Based on BMI $(p=0.002)$ and WC $(p=0.013)$ classification, the nutritional status was significantly influenced by Ramadan fasting as shown in Table 2 .

\begin{tabular}{|c|c|c|c|c|}
\hline \multirow{2}{*}{ Variables } & \multicolumn{2}{|c|}{ Groups (mean $\pm S D$ )/ \%age } & \multirow[b]{2}{*}{$P$ - Value } & \\
\hline & Pre-fasting & Post-fasting & & \\
\hline Weight (kg) & $79.08 \pm 116.35$ & $73.02 \pm 12.14$ & NS & \\
\hline Height $(\mathrm{cm})$ & $173.87 \pm 5.47$ & $174.16 \pm 6.25$ & NS & \\
\hline WC $(\mathrm{cm})$ & $89.65 \pm 13.92$ & $87.32 \pm 9.63$ & NS & \\
\hline $\mathrm{HC}(\mathrm{cm})$ & $100.26 \pm 11.18$ & $94.94 \pm 7.26$ & 0.01 & \\
\hline WHR $(\mathrm{cm})$ & $0.91 \pm 0.06$ & $0.89 \pm 0.07$ & NS & \\
\hline Body Fat (\%age) & $29.71 \pm 7.2$ & $23.83 \pm 5.7$ & 0.028 & \\
\hline $\mathrm{BMI}\left(\mathrm{kg} / \mathrm{m}^{2}\right)$ & $26.13 \pm 5.2$ & $24.14 \pm 3.5$ & 0.046 & \\
\hline BMR (kcal) & $1818.04 \pm 304.2$ & $1671.9 \pm 211.1$ & 0.012 & \\
\hline \multicolumn{5}{|l|}{ BMI } \\
\hline \multicolumn{2}{|c|}{ Normal (18.5-24.9) } & $58.4 .00 \%$ & $78.20 \%$ & \multirow{4}{*}{0.002} \\
\hline \multicolumn{2}{|c|}{ Underweight $(<18.5)$} & $16.6 .00 \%$ & $12.10 \%$ & \\
\hline \multicolumn{2}{|c|}{ Overweight (25-29.99) } & $13.80 \%$ & $6.10 \%$ & \\
\hline \multicolumn{2}{|c|}{ Obese $(>30)$} & $11.20 \%$ & $3.60 \%$ & \\
\hline \multicolumn{5}{|c|}{ Central Obesity (WC) } \\
\hline \multicolumn{2}{|l|}{ Normal $(W C<80)$} & $50.90 \%$ & $60.50 \%$ & \\
\hline \multicolumn{2}{|c|}{ Overweight $(\mathrm{WC}=80-88)$} & $29.20 \%$ & $24.60 \%$ & 0.013 \\
\hline \multicolumn{2}{|c|}{ Central OB (WC >88) } & $19.90 \%$ & $14.90 \%$ & \\
\hline
\end{tabular}

$W C=$ Waist circumference, $\mathrm{HC}=$ Hip circumference WHR $=$ Waist to hip ratio, $\mathrm{BMI}=$ Body mass index $\mathrm{BMR}=$ Basal metabolic rate

\section{Dietary macro and micronutrient intake}

The mean level of macronutrients (energy, protein, fats, carbohydrates, PUFA), vitamins (A, D, E, K, niacin, pantothenic acid, B6, biotin) and minerals (magnesium, phosphorous, zinc, iodine) at prefasting was significantly $(p=0.05)$ higher than postfasting (Figure 3 and 4).

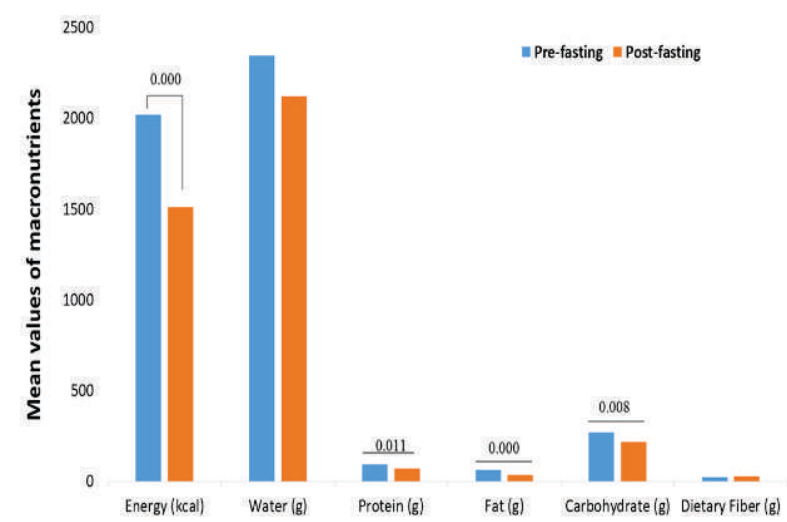

Fig 3: Macronutrients intake of the students 101

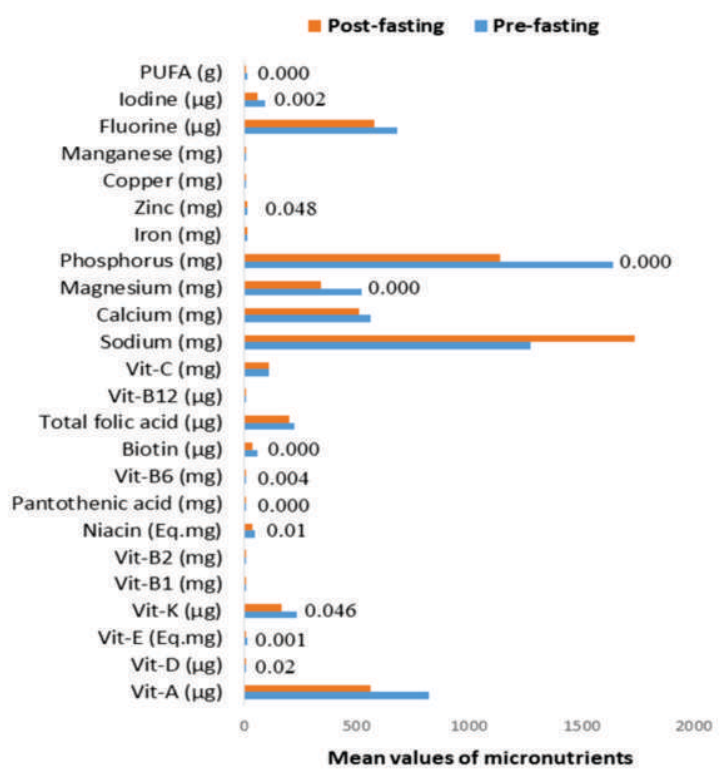

Fig 4: Macronutrients intake of the students

Correlation of physical activity, sleeping duration and body composition with nutrients intake

After product moment Pearson correlation, the results showed that dietary fat intake was significantly positive correlated with percentage fat, $\mathrm{BMI}$ and $\mathrm{BMR}$. The total energy was correlated with sleep arousal. Dietary fiber showed significant positive correlation with TST. This indicates that appropriate dietary fiber intake could improve the sleeping pattern of individuals. Vitamin A, D, E and K were also positive correlated with sleep latency, sleep arousal, physical activity, BMI and BMR. Niacin, pantothenic acid, vit-B6, biotin, vit- $\mathrm{C}, \mathrm{Na}, \mathrm{Mg}$ and $\mathrm{P}$ had significant negative correlation with age. Additionally, significant positive correlations of biotin, vitamin $\mathrm{C}$, iron and iodine with SL; pantothenic acid, calcium and iodine with SA; and folic acid, potassium and copper with TST were observed. There was a statistically positive correlation of $\mathrm{P}, \mathrm{Cu}$ and $\mathrm{F}$ with $\mathrm{BMI}$ and $\mathrm{BMR}$, while polyunsaturated fatty acids (PUFA) had significant negative correlation with WHR (Table 3).

\section{Discussion}

This study demonstrated that RF has significant impact on the nutritional status and nutrients intake of the international students associated with physical activity and sleeping pattern. We observed a non-significant difference in the sleeping pattern of the students. These findings are in line with a previous study reported a non-significant difference 


\begin{tabular}{|c|c|c|c|c|c|c|c|c|c|c|}
\hline Nutrients & Age & PA & SL & SA & TST & HC & WHR & Fat (\%) & BMI & BMR \\
\hline Energy & -0.154 & 0.194 & 0.181 & $0.208^{*}$ & 0.082 & 0.127 & 0.161 & 0.003 & 0.084 & 0.149 \\
\hline Protein & -0.191 & 0.146 & 0.133 & 0.157 & 0.055 & 0.097 & -0.041 & 0.025 & 0.076 & 0.159 \\
\hline Fat & -0.203 & 0.112 & 0.150 & 0.121 & -0.088 & 0.066 & $0.144^{*}$ & $0.267^{*}$ & $0.240^{*}$ & $0.242^{* *}$ \\
\hline Carbohydrate & -0.06 & 0.196 & 0.154 & $0.208 *$ & 0.180 & 0.131 & 0.162 & 0.037 & 0.096 & 0.113 \\
\hline Dietary fiber & 0.121 & 0.023 & 0.170 & 0.041 & $0.214^{*}$ & 0.015 & 0.062 & 0.024 & 0.046 & 0.009 \\
\hline Vit-A & 0.063 & 0.186 & $0.325 * *$ & $0.240 *$ & -0.067 & 0.195 & 0.079 & 0.182 & $0.273^{* *}$ & $0.264^{*}$ \\
\hline Vit-D & -0.049 & 0.186 & $0.304 * *$ & 0.179 & -0.169 & 0.014 & -0.036 & -0.012 & 0.075 & 0.097 \\
\hline Vit-E & -0.083 & 0.172 & 0.007 & $0.299 * *$ & 0.041 & 0.068 & -0.099 & 0.075 & 0.089 & 0.082 \\
\hline Vit-K & 0.000 & $0.211 *$ & $0.184^{*}$ & 0.169 & -0.172 & 0.199 & 0.071 & 0.143 & $0.245^{*}$ & $0.231 *$ \\
\hline Vit-B $B_{1}$ & -0.016 & 0.172 & 0.023 & 0.114 & 0.132 & -0.018 & -0.074 & 0.016 & -0.01 & 0.082 \\
\hline Vit-B ${ }_{2}$ & 0.169 & 0.028 & 0.057 & 0.033 & 0.155 & 0.007 & 0.059 & 0.081 & 0.053 & -0.059 \\
\hline Niacin & $-0.296 * *$ & 0.107 & -0.006 & 0.091 & 0.113 & -0.006 & -0.084 & 0.003 & 0.018 & 0.037 \\
\hline Pantothenic acid & $-0.274 * *$ & 0.146 & 0.180 & $0.216^{*}$ & 0.078 & 0.081 & -0.140 & -0.023 & 0.086 & 0.144 \\
\hline Vit-B 6 & $-0.24 *$ & 0.143 & 0.083 & 0.139 & 0.166 & 0.180 & -0.166 & 0.052 & 0.118 & $0.220 *$ \\
\hline Biotin & $-0.231 *$ & $0.221 *$ & $0.217^{*}$ & 0.199 & 0.080 & 0.145 & -0.106 & 0.064 & 0.173 & 0.204 \\
\hline Folic acid & 0.025 & $0.211 *$ & 0.157 & 0.130 & $0.213^{*}$ & 0.116 & -0.017 & 0.070 & 0.119 & 0.098 \\
\hline $\mathrm{B}_{12}$ & 0.117 & -0.017 & 0.119 & 0.152 & 0.078 & -0.013 & 0.078 & 0.048 & 0.029 & -0.006 \\
\hline Vit-C & $0.225 *$ & 0.155 & $0.247^{*}$ & 0.177 & -0.080 & 0.044 & 0.086 & 0.086 & 0.04 & 0.09 \\
\hline Sodium & $0.242 *$ & -0.014 & 0.126 & 0.078 & 0.008 & -0.086 & 0.043 & -0.008 & -0.093 & -0.177 \\
\hline Potassium & 0.057 & 0.043 & 0.113 & 0.074 & $0.255^{*}$ & 0.10 & -0.032 & 0.091 & 0.081 & 0.142 \\
\hline Calcium & 0.097 & 0.137 & -0.005 & $0.255^{*}$ & -0.086 & 0.025 & -0.049 & -0.032 & -0.01 & 0.019 \\
\hline Magnesium & $-0.26^{*}$ & $0.290 * *$ & 0.176 & 0.178 & 0.093 & $0.251 *$ & -0.159 & 0.057 & 0.176 & $0.273^{* *}$ \\
\hline Phosphorous & $-0.274^{* *}$ & $0.227^{*}$ & 0.156 & 0.160 & 0.077 & 0.195 & -0.113 & 0.019 & 0.144 & $0.232 *$ \\
\hline Iron & -0.009 & 0.118 & $0.286 * *$ & 0.124 & 0.148 & 0.201 & -0.010 & 0.097 & 0.164 & 0.193 \\
\hline Zinc & -0.019 & 0.205 & 0.132 & 0.132 & 0.019 & 0.159 & 0.058 & 0.059 & 0.156 & 0.201 \\
\hline Copper & -0.008 & 0.146 & 0.137 & 0.158 & $0.292^{* *}$ & 0.185 & -0.014 & 0.101 & 0.20 & $0.258^{*}$ \\
\hline Fluorine & 0.011 & 0.118 & 0.143 & 0.176 & -0.031 & 0.159 & 0.065 & 0.088 & $0.224^{*}$ & $0.237^{*}$ \\
\hline lodine & 0.023 & $0.260 *$ & $0.260^{*}$ & $0.297^{* *}$ & -0.120 & 0.097 & -0.060 & 0.012 & 0.103 & 0.145 \\
\hline PUFA & -0.198 & 0.140 & 0.040 & 0.131 & -0.109 & 0.106 & $-0.262^{*}$ & -0.04 & 0.017 & 0.081 \\
\hline
\end{tabular}

$* *=p<0.001 ; *=p<0.05, \mathrm{PA}=$ physical activity, $\mathrm{SL}=$ Sleep latency, $\mathrm{SA}=\mathrm{Sleep}$ arousal, $\mathrm{TST}=$ Total sleep time

$\mathrm{HC}=$ Hip circumference, $\mathrm{WHR}=$ Waist to hip ratio, $\mathrm{BMI}=$ Body mass index, $\mathrm{BMR}=$ Basel metabolic rate

PUFA= Polyunsaturated fatty acid

in TST, sleep efficiency, sleep-onset latency and rapid eye moment (REM)-onset latency between the baseline (BL), baseline fasting (BLF), during Ramadan and recovery periods. ${ }^{33}$ In a review of the effect of Ramadan intermittent fasting (RIF) on sleeping pattern and circadian rhythm controlled for sleep or wake pattern and environmental factors, a nonsignificant difference in sleep architecture is shown. ${ }^{34}$ In addition, a one-week home based modifiable experimental fasting, reported no difference in sleep latency (SL). ${ }^{35}$ Another study also observed that sleep latency was not changed in the first and third week of Ramadan. ${ }^{36}$ Other previous studies have reported some contradictory results on the effects of fasting on sleep latency (SL). In a study of subjects practicing $\mathrm{RF}$, showed that SL was increased during Ramadan. ${ }^{6,37}$ A recent study reported that during Ramadan, many of the subjects appeared to have much reduced TST. ${ }^{38}$ The difference in results regarding SL and TST between the previous and the current study can reflect different study protocols used to report such findings.

In contrast to our findings, a previous study reported that overall sleep duration was reduced as Ramadan progresses. This is commonly reported for adults. ${ }^{39,40}$ The reason that people are very busy in preparation for festival (Eid-ul-fitr) at the end of Ramadan, in addition they also engage in, last night prayers and worship. However, these factors may be attributable to reduce the total sleep time. In the present study, the TST was reported with in recommended range, may be because those students were living in university hostels and had no extra activities during night time. In our study, sleep efficiency was observed $86 \%$ that reflect the normal sleeping pattern of university students, as reported previously. ${ }^{41}$

Findings from some activity pattern parameters of this study are in line with previous reports during Ramadan. ${ }^{42,43}$ A study on elite karate athletes showed that Ramadan intermittent fasting (RIF) did not badly affect the neuromuscular performances and anthropometric measures during their usual training. ${ }^{44}$ Most recent evidence from wellcontrolled studies supported that athletes who maintain their macronutrient intake, body composition, training load, sleep length are unlikely to grieve from any considerable decrements in 
physical performance during Ramadan. ${ }^{45}$

Body composition findings of our study are supported by a previous study which reported a decrease in weight and BMI of Iranian individuals during $\mathrm{RF}$, as indicated a significant decrease in $\mathrm{BMI}$, weight and WC. ${ }^{46}$ Ziaee and colleagues also reported a decrease in $\mathrm{BMI}$ and body composition among 41 men. ${ }^{47}$ In our study, the mean percentage body fat, WHR and body weight were lowered by Ramadan fasting and the same mean was recorded by a study on 160 individuals during Ramadan fasting in kermanshah, Iran. ${ }^{48}$

Previous studies supported that during Ramadan fasting, body fat mass and weight are reduced, ${ }^{49-55}$ indicating the negative energy balance state of the individuals. Similarly, our results also suggested a decline in body weight, WHR, BMI, body fat percentage, $W C$ and $B M R$. The mean BMR was significantly $(p=0.01)$ reduced after Ramadan, indicating that fasting maintain the body metabolism in optimal range which has significant effects on health and nutritional status. Inconsistent to our results a study reported the mean BMR (1400) of 19 individuals during Ramadan, this difference may be due to their small sample size and aged study participants. ${ }^{56}$

Changes in feeding pattern and nutrient intake are very common during Ramadan fasting, therefore the changes in total energy intake of our findings are in line with previous results reported in Indian, ${ }^{57}$ and Algerian Muslims. ${ }^{58}$ In comparison of macronutrient intake, we observed a significant difference in total energy intake, protein, fat and carbohydrates except water while a non-significant difference in dietary fiber after fasting compared to baseline. The observed differences in protein and carbohydrates intake are in agreement, while decrease in fat intake is in contrast with other studies during Ramadan. ${ }^{59-61}$ The significant lower macronutrients intake are in line with a study on food intake during the month of Ramadan in 71 Moroccan patients with type 2 diabetes. ${ }^{62,48}$ Our results showed significantly lower mean intake of micronutrients (vitamins $A, D, E, K$, niacin, $\mathrm{B}_{6}$ ) and minerals ( $\mathrm{Mg}$, phosphorous, zinc, iodine) and PUFA, while non-significant decrease in remaining nutrients after Ramadan compared to baseline. In a study on 70 participants conducted in the khvormuj city of Iran reported a significant decrease in the mean intake of vitamin $E, K, B_{2}, B_{1}$, folate, niacin, calcium, phosphorous, copper, sodium, iron and manganese while a significant increase in pyridoxine, vitamin $D, A, C$ and potassium after Ramadan compared to baseline. ${ }^{63}$

It is notable that this is the very first study to determine the international student's nutrient intake association with physical activity, sleeping pattern and body composition during RF. However, studies have failed to report any correlation between body composition, BMI and individual nutrients, food items and dietary patterns. Only few researchers have demonstrated the correlation between sleeping pattern and nutrient intake, however, confirmatory results has yet to be established for management of sleeping disorders through nutritional therapy. We found a positive significant correlation of carbohydrate with disturb sleep pattern. Similarly, a study reported that increase in fat and carbohydrate intake cumulatively affects energy balance and sleeping duration that leads to overweight and obesity. ${ }^{64}$ There was no significant interaction of carbohydrate with BMI and $B M R$, which is similar to a study, reported no significant association between $\mathrm{BMI}$ and percent carbohydrate intake in obese people. ${ }^{65}$ Some existing literature suggest that certain nutrients have strong impact on sleep by changing the people neural responses like vitamin B complex group causes psychological distress that leads to sleep disorder. ${ }^{66,67}$ The other macro nutrient that is important with respect to sleep disturbance is carbohydrates. ${ }^{68}$ Excess carbohydrate intakes reduce the quality of sleep through secretion of serotonin by midnight waking. ${ }^{25,69}$ There is no such study on association of protein with sleep; however, possibilities that tryptophan and tyrosine are potent sleep enhancers, and could promote sleep quality by providing adequate dietary protein. ${ }^{70}$ Riboflavin, niacin, $\mathrm{B}_{6}$, and folic acid have positive association with sleeping pattern and improve the sleeping quality. Vitamin $B_{12}$ has significant effect on biological rhythm, as evidenced that supplementation of $B_{12}$ improves the symptoms of sleep arousal disorder. ${ }^{71}$

The appropriate analysis of the current study can be a valuable initial step for the study and further longitudinal researches are required to be conducted to investigate these impacts in adolescent 
university students both male and female., We do not know if there are students belonging to the same household, but they were all living in university hostels; it is impossible to justify for the effects of RF between students from the same household. The present study has some acknowledgeable strength. The associations between sleeping, activity patterns, body composition and dietary intake were evaluated examining specific nutrients rather than dietary patterns. The current study focusing on gathering the nutrient intakes during RF may help to achieve a better understanding of nutritional status and caloric restriction concept assumed of having important health outcomes.

\section{Conclusion}

Ramadan Fasting has potential to maintain optimal nutritional status by regulating the normal weight, BMI, WHR and BMR of the students. Ramadan fasting has no adverse effects on health status of the students indicating health safety while practicing fasting. Fasting can support the concept of caloric restriction to improve the health efficiency. During $\mathrm{RF}$, recommended dietary fiber, folic acid, iron, iodine and PUFA intake are important for proper physical activity, adequate sleeping and reducing obesity.

\section{Acknowledgements}

The authors are grateful to all students who fully participated in the study. We indebted to the universities administration for their moral support. We also thankful to nutrition assistants for their data collection and screening. We are also grateful to Priority Academic Program Development of Jiangsu Higher Education Institutions for financial support of this research project.

\section{REFERENCES}

1. Hassanein M, Al-Arouj M, Hamdy O, Bebakar WMW, Jabbar A, Al-Madani A, et al. Diabetes and Ramadan: practical guidelines. Diabetes Res Clin Pract. 2017; 126: 303-16.

2. Frost G, Pirani S. Meal frequency and nutritional intake during Ramadan: a pilot study. Hum Nutr Appl Nutr. 1987; 41:47-50.

3. Hatori M, Vollmers C, Zarrinpar A, DiTacchio L, Bushong EA. Time-restricted feeding without reducing caloric intake prevents metabolic diseases in mice fed a high-fat diet. Cell Metab. 2012; 15:848-60.

4. Bass J, Takahashi JS. Circadian integration of metabolism and energetics. Science. 2012; 330: 1349-54.

5. Taoudi BM, Roky R, Toufiq J, Benaji B, Hakkou F.
Epidemiological study: chronotype and daytime sleepiness before and during Ramadan. Therapie. 1999; 54: 567-72.

6. Roky R, Chapotot F, Hakkou F, Benchekroun MT, Buguet A. Sleep during Ramadan intermittent fasting. J Sleep Res. 2001; 10: 319-27.

7. Burke LM, King C. Ramadan fasting and the goals of sports nutrition around exercise. J Sports Sci. 2012; 30: S21-S31.

8. Bogdan A, Bouchareb B, Touitou Y. Ramadan fasting alters endocrine and neuroendocrine circadian patterns. Mealtime as a synchronizer in humans? Life Sci. 2001; 68: 1607-15.

9. Bahijri S, Borai A, Ajabnoor G, Abdul Khaliq A, AlQassas I, AlShehri D, et al. Relative metabolic stability, but disrupted circadian cortisol secretion during the fasting month of Ramadan. PLoS One. 2013; 8: e60917.

10. Bogdan A, Bouchareb B, Touitou Y. Response of circulating leptin to Ramadan daytime fasting: a circadian study. $\mathrm{Br} J$ Nutr. 2005; 93: 515-8.

11. Bouhlel E, Denguezli M, Zaouali M, Tabka Z, Shephard RJ. Ramadan fasting effect on plasma leptin, adiponectin concentrations, and body composition in trained young men. Int J Sport Nutr Exerc Metab. 2008; 18: 617-27.

12. Kassab S, Abdul-Ghaffar T, Nagalla DS, Sachdeva U, Nayar U. Interactions between leptin, neuropeptide-Y and insulin with chronic diurnal fasting during Ramadan. Ann Saudi Med. 2004; 24: 345-9.

13. Finch GM, Day JE, Razak, Welch DA, Rogers PJ. Appetite changes under free-living conditions during Ramadan fasting. Appetite. 1998; 31: 159-70.

14. Bouhlel E, Salhi Z, Bouhlel H. Effect of Ramadan fasting on fuel oxidation during exercise in trained male rugby players. Diabetes Metab. 2006; 32: 617-24.

15. Racinais S, Periard JD, Li CK, Grantham J. Activity patterns, body composition and muscle function during ramadan in a Middle-East Muslim country. Int J Sports Med. 2012; 33: 641-6.

16. Al-Hourani HM, Atoum MF. Body composition, nutrient intake and physical activity patterns in young women during Ramadan. Singapore Med J. 2007; 48: 906-10.

17. Bakhotmah BA. The puzzle of self-reported weight gain in a month of fasting (Ramadan) among a cohort of Saudi families in Jeddah, Western Saudi Arabia. Nutr J. 2011; 10: 84.

18. Lamine F, Bouguerra R, Jabrane J, Marrakchi Z, Ben Rayana MC, Ben Slama C, et al. Food intake and high density lipoprotein cholesterol levels changes during ramadan fasting in healthy young subjects. Tunis Med. 2006; 84: 647-50.

19. Hajek P, Myers K, Dhanji AR, West O, McRobbie H. Weight change during and after Ramadan fasting. J Pub Health. 2012; 34:377-81.

20. Khaled BM, Belbraouet S. Effect of Ramadan fasting on anthropometric parameters and food consumption in 276 type 2 diabetic obese women. Int J Diabetes Dev Ctries. 2009; 29: 62-8.

21. Hasler G, Buysse DJ, Klaghofer R. The association between short sleep duration and obesity in young adults: a 13-year prospective study. Sleep. 2004; 27: 661-6.

22. Spiegel K, Tasali E, Penev P, Van Cauter E. Brief 
communication: sleep curtailment in healthy young men is associated with decreased leptin levels, elevated ghrelin levels, and increased hunger and appetite. Ann Intern Med. 2004; 141: 846-50.

23. Spiegel K, Knutson K, Leproult R, Tasali E, Van Cauter E. Sleep loss: a novel risk factor for insulin resistance and type 2 diabetes. J Appl Physiol. 2005; 99: 2008-19.

24. Knutsson A. Relationships between serum triglycerides and g-glutamyltransferase among shift and day workers. J Intern Med. 1989; 226: 337-9.

25. Afaghi A, O'Connor $\mathrm{H}$, Chow CM. High-glycemic-index carbohydrate meals shorten sleep onset. Am J Clin Nutr. 2007; 85: 426-30.

26. Alkandari JR, Maughan RJ, Roky R, Aziz AR, Karli U. The implications of Ramadan fasting for human health and wellbeing. J Sports Sci. 2012; 30: S9-S19.

27. Afifi ZE. Daily practices, study performance and health during the Ramadan fast. J R Soc Health. 1997; 117: 231-5.

28. BaHammam A, Alrajeh $M$, Albabtain $M$, Bahammam $S$, Sharif M. Circadian pattern of sleep, energy expenditure, and body temperature of young healthy men during the intermittent fasting of Ramadan. Appetite. 2010; 54:426-9.

29. Barkia A, Mohamed K, Smaoui M. Change of diet, plasma lipids, lipoproteins, and fatty acids during Ramadan: a controversial association of the considered Ramadan model with atherosclerosis risk. J Health Popul Nutr. 2011; 29: 48693.

30. Guerrero M, Ramírez R, Sánchez C. Dietary modifications, in young Muslims engaged in Ramadan fasting. Nutr Hosp. 2008; 24: 738-43.

31. Jasper HH. The ten-twenty electrode system of the international federation. Electroencephalogr Clin Neurophysiol. 1958; 10: 371-5.

32. Iber C, Ancoli-Israel S, Chesson A Jr, Quan S. The AASM manual for the scoring of sleep and associated events: rules, terminology, and technical specification, 1st, American Academy of Sleep Medicine, Westchester, IL 2007.

33. Bahammam AS, Almushailhi K, Pandi-Perumal SR, Sharif $\mathrm{MM}$. Intermittent fasting during Ramadan: does it affect sleep? J Sleep Res. 2014; 23:35-43.

34. Qasrawi SO, Pandi-Perumal SR, BaHammam AS. The effect of intermittent fasting during Ramadan on sleep, sleepiness, cognitive function, and circadian rhythm. Sleep Breath. 2017; 21:577-86.

35. Michalsen A, Schlegel F, Rodenbeck A. Effects of shortterm modified fasting on sleep patterns and daytime vigilance in non-obese subjects: results of a pilot study. Ann Nutr Metab. 2003; 47: 194-200.

36. BaHammam A. Effect of fasting during Ramadan on sleep architecture, daytime sleepiness and sleep pattern. Sleep Biol. Rhythm. 2004; 2: 135-43.

37. Roky R, Chapotot F, Benchekroun MT. Daytime sleepiness during Ramadan intermittent fasting: polysomnographic and quantitative waking EEG study. J. Sleep Res. 2003; 12: 95-101.

38. Lessan N, Saadane I, Alkaf B, Hambly C, Buckley AJ, Finer N, et al. The effects of Ramadan fasting on activity and energy expenditure. Am J Clin Nutr. 2018; 107: 54-61.

39. Roky R, Chapotot F, Hakkou F, Benchekroun MT, Buguet A.
Sleep during Ramadan intermittent fasting. J Sleep Res. 2001; 10: 319-27.

40. Herrera CP. Total sleep time in Muslim football players is reduced during Ramadan: A pilot study on the standardized assessment of subjective sleep-wake patterns in athletes. J Sports Sci. 2012; 30: S85-S91.

41. Farooq A, Herrera CP, Almudahka F, Mansour R. A Prospective Study of the Physiological and Neurobehavioral Effects of Ramadan Fasting in Preteen and Teenage Boys. J Acad Nutr Diet. 2015; 115: 889-97.

42. Racinais S, Periard JD, Li CK, Grantham J. Activity patterns, body composition and muscle function during ramadan in a Middle-East Muslim country. Int J Sports Med. 2012; 33: 641-6.

43. Zarrouk N, Hammouda O, Latiri I, Adala H, Bouhlel E, Rebai H. Ramadan fasting does not adversely affect neuromuscular performances and reaction times in trained karate athletes. J Int Soc Sports Nutr. 2016; 13: 18.

44. Chaouachi A, Leiper JB, Chtourou H, Aziz AR, Chamari K. The effects of Ramadan intermittent fasting on athletic performance: recommendations for the maintenance of physical fitness. J Sports Sci. 2012; 30: S53-73.

45. Nematy M, Alinezhad-Namaghi M, Rashed MM. Effects of Ramadan fasting on cardiovascular risk factors: a prospective observational study. Nutr J. 2012;11: 1.

46. Ziaee $V$, Razaei M, Ahmadinejad Z. The changes of metabolic profile and weight during Ramadan fasting. Singapore Med J. 2006; 47: 409.

47. Nachvak SM, Pasdar Y, Pirsaheb S, Darbandi M, Niazi P, Mostafai R. Effects of Ramadan on food intake, glucose homeostasis, lipid profiles and body composition composition. Eur J Clin Nutr. 2018.

48. Nugraha B, Ghashang SK, Hamdan I, Gutenbrunner C. Effect of Ramadan fasting on fatigue, mood, sleepiness, and health-related quality of life of healthy young men in summer time in Germany: a prospective controlled study. Appetite. 2017; 111:38-45.

49. Sezen Y, Altiparmak IH, Erkus ME, Kocarslan A, Kaya Z, Gunebakmaz O. Effects of Ramadan fasting on body composition and arterial stiffness. J Pak Med Assoc. 2016; 66:1522-7.

50. Yeoh EC, Zainudin SB, Loh WN, Chua CL, Fun S, Subramaniam T. Fasting during ramadan and associated changes in glycaemia, caloric intake and body composition with gender differences in Singapore. Ann Acad Med Singap. 2015; 44: 202-6.

51. López-Bueno M, González-Jiménez E, Navarro-Prado S, Montero-Alonso MA, Schmidt-RioValle J. Influence of age and religious fasting on the body composition of Muslim women living in a westernized context. Nutr Hosp. 2014; 31 : 1067-73.

52. Reiches MW, Moore SE, Prentice AM, Ellison PT. Endocrine responses, weight change, and energy sparing mechanisms during Ramadan among Gambian adolescent women. Am J Hum Biol. 2014; 26: 395-400.

53. Norouzy A, Salehi M, Philippou E, Arabi H, Shiva F, Mehrnoosh S. Effect of fasting in Ramadan on body composition and nutritional intake: a prospective study. J Hum Nutr Diet. 2013; 1: 97-104. 
54. Maughan RJ, Bartagi Z, Dvorak J, Zerguini Y. Dietary intake and body composition of football players during the holy month of Ramadan. J Sports Sci. 2008; 26: S29-38.

55. Sadiya A, Ahmed S, Siddieg HH, Babas IJ, Carlsson M. Effect of Ramadan fasting on metabolic markers, body composition, and dietary intake in Emiratis of Ajman (UAE) with metabolic syndrome. Diabetes Metab Syndr Obes. 2011; 4: 409-16.

56. Ahmadi A, Hajiani N, Keshavarzi S. Anthropometric Index and Diet Pattern of Fasting Men in Khvormuj. Int J Nutr Sci. 2017; 2: 27-32.

57. Lamri-Senhadji MY, El-Kebir B, Belleville J, Bouchenak M. Assessment of dietary consumption and time-course of changes in serum lipids and lipoproteins before, during and after Ramadan in young Algerian adults. Singapore Med J. 2009; 50: 288-94.

58. El-Ati J, Beji C, Danguir J. Increased fat oxidation during Ramadan fasting in healthy women: an adaptive mechanism for body weight maintenance. Am J Clin Nutr. 1995; 62: 302-7.

59. Wissam HI, Hosam MH, Amjad HJ, Samer AAB. Effect of Ramadan fasting on markers of oxidative stress and serum biochemical markers of cellular damage in healthy subjects. Ann Nutr Metab. 2008; 53: 175-81.

60. Khaled BM, Belbraouet S. Ramadan Fasting Diet Entailed a Lipid Metabolic Disorder among Type 2 Diabetic Obese Women. American Journal of Applied Sciences. 2009; 6 : 471-7.

61. Sebbani M, El Ansari N, El Mghari G, Amine M. Food intake during the month of Ramadan in Moroccan patients with type 2 diabetes. East Mediterr Health J. 2013; 19: 276-81.

62. Hassapidou M, Fotiadou E, Maglara E, Papadopoulou SK. Energy intake, diet composition, energy expenditure, and body fatness of adolescents in Northern Greece. Obesity. 2006; 14: 855-62.

63. Bahammam AS, Nashwan S, Hammad O, Sharif MM, PandiPerumal SR. Objective assessment of drowsiness and reaction time during intermittent Ramadan fasting in young men: a case-crossover study. Behav Brain Funct. 2013; 9: 32.

64. Brown RE, Sharma AM, Ardern Cl, Mirdamadi P, Mirdamadi $P$, Kuk JL. Secular differences in the association between caloric intake, macronutrient intake, and physical activity with obesity. Obes Res Clin Pract. 2016; 10: 243-55.

65. Porter JM, Horne JA. Bed-time food supplements and sleep: effects of different carbohydrate levels. Electroencephalogr Clin Neurophysiol. 1981; 51: 426-33.

66. Bernstein AL. Vitamin B6 in clinical neurology. Ann N Y Acad Sci. 1990; 585: 250-60.

67. Lichstein KL, Payne KL, Soeffing JP, Heith Durrence H, Taylor DJ, Riedel BW, et al. Vitamins and sleep: an exploratory study. Sleep Med. 2007; 9: 27-32.

68. Allen RP, Earley CJ. Restless legs syndrome: a review of clinical and pathophysiologic features. J Clin Neurophysiol. 2001; 18: 128-47.

69. Hajak G, Rodenbeck A, Staedt J, Bandelow B, Huether G, Rüther $\mathrm{E}$. Nocturnal plasma melatonin levels in patients suffering from chronic primary insomnia. J Pineal Res. 1995; 19: 11622.

70. Hudson C, Hudson SP, Hecht T, MacKenzie J. Protein source tryptophan versus pharmaceutical grade tryptophan as an efficacious treatment for chronic insomnia. Nutr Neurosci. 2005; 8: 121-7.

71. Ohta T, Ando K, Iwata T, Ozaki N, Kayukawa Y, Terashima M, et al. Treatment of persistent sleep-wake schedule disorders in adolescents with methylcobalamin (vitamin B12). Sleep. 1991; 14: 414-8. 